\title{
China's New Normal of Economy and the Optimization and Upgrading of the Economic Structure
}

\author{
Lin Cheng, \\ dept. of Marxism Theory \\ Xi'an Politics Institute of PLA \\ Xi'an, China \\ linch@sina.com
}

\begin{abstract}
In recent years, China's economy has witnessed great changes in terms of growth rate, structural adjustment and the motive force of development. Therefore, China' economy has stepped into the new normal. The main change under the new normal is the optimization and upgrading of the economic structure, which is also the new challenge to achieve the economic sustainable development. Under the background of the economic new normal, economic structure can be optimized and upgraded only by deepening the reform, eliminating the institutional barriers which impede the free flow of elements, making market play a decisive role in resources allocation and ensuring the government paly a greater role. The concrete measures include: to promote the development of new-type urbanization, to construct modern industrial system and to further regional economic integration. All these measures will give new motive power to the economic development of China.
\end{abstract}

Keywords- New Normal of Economy; Economic Structu re; Optimization and Upgrading; Deepening the Reform.

\section{INTRODUCTION}

China' new normal, which is the senior Chinese officials' high generalization on the stage characteristics of the current economic development, indicates that there are 3 characteristics in China's economic development, which are the change of rate, the optimization of structure and the transformation of motive power. The main change brought about by the new normal of economic development is the optimization and upgrading of the economic structure. Therefore, in order to promote the sustainable and healthy development of economy, it is of great significance to analyze the challenges and chances of the optimization and upgrading of the economic structure in depth.

\section{THE OPTIMIZATION AND UPGRADING OF THE ECONOMIC STRUCTURE ARE THE MAIN CHANGE UNDER CHINA'S NEW NORMAL.}

At present, China's economic development has stepped into the new normal and is obviously different from the economic development in the past in terms of the growth rate, structural adjustment and the motive force of development. All the changes have their own profound social and economic backgrounds.

The first background is that China's economic scale is quite large after the rapid development for 30 years since reform and opening-up. For 30 years since reform and opening-up, the average annual growth rate of China's GDP reaches up to $9.8 \%$. In 2013, the proportion of China's GDP on the world's GDP rose up to $12 \%$. In 2014, China became the second county whose GDP exceeded 10 trillion.

The second background is that the traditional economic development mode is hard to carry on, so the "growing pains" appear. Various contradictions and problems such as the imbalance in income distribution, the disappearance of demographic dividend, the greater pressure on resources and environment, production capacity surplus and so on, appear in the current economic and social development of China. These contradictions and problems are the adverse effects brought about by the traditional development mode and have to be solved gradually by deepening the reform and adjusting the structure.

The third background is that the global economy has not stepped out of the shadow of the financial crisis in 2008 and has been trapped in the "new mediocrity". The international financial crisis in 2008, which now appears in the form of European sovereign debt crisis, severely limits the world economic recovery. The depression of global economy leads to the poor overseas market demand, therefore, the economic growth has to be stimulated by domestic demand.

As stated by Chinese president Xi Jingping at APEC Conference in November, 2014, China's new normal takes on 3 main features: the first one is the transfer from highspeed growth to medium-to-high speed of growth; the second one is the continuous optimization and upgrading of the economic structure: The third industry and the consumption demand have gradually become the economic subjects; the gap between urban and rural areas are gradually narrowed down; the proportion of the residents' income is rising and the economic success has benefited more people. The third one is the transfer from factordriven and investment-driven growth to innovation-driven growth. In December, 2014, President Xi Jingping stated the nine trend changes at the central economic work conference when he stressed that China's economy has stepped into a phase with more advanced form, more complex division of labor and more reasonable structure.

Both the slowing down of the growth rate and the transfer of the motive force of development are closely related to the change of economic structure. Economic structure includes the industrial structure, industrial 
organization, resource endowment, the consumption structure as well as demographic structure, urban and rural structure and regional structure. The slowing down of the current economic growth rate in China is caused by the changes in demographic structure, resource endowment and industrial structure. These changes include the disappearance of demographic dividend, greater constraint on resources and environment and the adjustment of the real estate market and so forth. Of course, the slowing down of the economic growth rate also has something to do with the economic woes faced by the developed economies as America, Japan and Europe. China's economic development has stepped into the new normal, which provides opportunities for the optimization and upgrading of the economic structure. As the traditional economic development mode comes to an end, labor cost will increase; the prices of production factors will be higher; consumption demand will upgrade and the environmental policies of the government will be more severe. Thus, innovation will gradually take the place of factors and investment and become the main motive force of development.

In fact, the process of optimizing and upgrading economic structure is the process of resource optimal allocation, in which the population and production factors will be transferred from the relatively low efficient regions, industries and posts to the higher efficient regions, industries and posts. The motive forces of economic development include the main demands for investment, consumption and export on short terms while on long terms include the input of factors as labor and capital etc. as well as the system reform, structural optimization and factor upgrading etc. which will increase total factor productivity (TFP). In addition, with the improvement of economic development level, the latter will play a greater role.

As China's economy steps into the new normal, the growth rate has been slowed down and the structure of the motive force has been changed. Meanwhile, the third industry and the consumption demand have gradually taken the place of the secondary industry and the investment demand and have become the economic subjects; the gap between urban and rural areas is narrowed down step by step; the regional economic integration has been accelerated; therefore, the optimization and upgrading of the economic structure will make more and more contribution to the economic development. In view of this, it is reasonable to conclude that the optimization and upgrading of the economic structure is the main change underChina's new normal.

\section{THE OPTIMIZATION AND UPGRADING OF THE ECONOMIC STRUCTURE ARE FACING A RARE HIST ORIC OPPORTUNITY.}

Under the new normal, the optimization and upgrading of China's economic structure are facing a rare historic opportunity. The promotion of the new-type urbanization, the upgrading of the industrial system and the regional economic integration including the "One Belt and One Road" strategy will become the inexhaustible motive power for the economic development in China.

Firstly, the new-type urbanization has a great potential. Because there obviously exists the urban-rural dual structure in China, the infrastructure in rural areas is much poorer, labor productivity is lower and the income, social security and social status of the rural residents are worse than those of the urban residents. Thus, farmers have a strong willingness to come to the cities. Urbanization means a great improvement of the whole national economic efficiency and the national income level. In the past 30 years, the urbanization of population and the foreign trade are the two main motive powers for the economic development in China. At the end of 2014, the urbanization ratio of China was $54.77 \%$ (table I ) and the ratio of household registration urbanization was only $36 \%$. It was obvious that the urbanization level of China was much lower than that of the developed countries and even lower than that of some developing countries such as India. According to the international experiences, when the urbanization ratio of a country or a region is between $30 \%$ and $70 \%$, the urbanization of that country or region has entered the stage of accelerated development. Obviously, China's urbanization is in the stage of accelerated development and the great potential of urbanization will continuously create investment demands and consumption demands to promote the optimization and upgrading of the economic structure.

TABLE I. ThE URBANIZATION RATIO IN ChINA (\%)

\begin{tabular}{|c|c|c|c|c|c|}
\hline Year & $\mathbf{2 0 1 0}$ & $\mathbf{2 0 1 1}$ & $\mathbf{2 0 1 2}$ & $\mathbf{2 0 1 3}$ & $\mathbf{2 0 1 4}$ \\
\hline Urbanization Ratio & 49.95 & 51.27 & 52.57 & 53.73 & 54.77 \\
\hline
\end{tabular}

Secondly, the upgrading of the industrial system has to be accelerated. There are two reasons for the upgrading of the industrial system: The first reason is that the industrial system has to be upgraded with the upgrading of the consumption structure. The second reason is that the higher factor cost cannot be covered without the upgrading of the industrial system. The proportion of the third industry is continuously rising and the third industry has gradually taken the place of the secondary industry to become the subjects of national economy. In 2014, the proportion of the third industry on GDP rose up to $48.2 \%$ while the proportion of the secondary industry decreased to $42.6 \%$ (table II). In spite of this, the proportion of the third industry is still much lower than the developed countries, even lower than India. In view of this, there is much room for the third industry to develop. The industries and fields related to the caring for the aged, medical care, hygiene, tourism, culture, logistics and internet will become the important economic growth points. Moreover, the IT industry, environmental protection and low carbon industries as well as the modern agricultural management system will also undergo greater development.

TABLE II. THE PROPORTION OF THREE INDUSTRY IN CHINA

\begin{tabular}{|c|c|c|c|}
\hline Year & $\begin{array}{c}\text { the first } \\
\text { industry }\end{array}$ & $\begin{array}{c}\text { the secondary } \\
\text { industry }\end{array}$ & $\begin{array}{c}\text { the Third } \\
\text { industry }\end{array}$ \\
\hline $\mathbf{2 0 1 0}$ & 10.1 & 46.7 & 43.2 \\
\hline $\mathbf{2 0 1 1}$ & 10.0 & 46.6 & 43.4 \\
\hline $\mathbf{2 0 1 2}$ & 10.1 & 45.3 & 44.6 \\
\hline $\mathbf{2 0 1 3}$ & 10.0 & 43.9 & 46.1 \\
\hline $\mathbf{2 0 1 4}$ & 9.2 & 42.6 & 48.2 \\
\hline
\end{tabular}

Thirdly, the regional economic integration enjoys a promising prospect. The regional economic integration 
helps to avoid the vicious competition and industrial isomorphism, lower the transaction costs and reduce redundant constructions. Besides, it helps to exploit comparative advantages and have the effect of cooperation based on division of labor so as to achieve the win-win development. At present, the regional economic integration in China is accelerating. The Yangtze River Delta region, Pearl River Delta region and Beijing-Tianjin area which were formed in the past will continue to develop, while the implementation of the grand strategies as the "One Belt and One Road" project and the Yangtze River Economic Belt have brought about a new tide of regional economic integration. "One Belt and One Road", which refers to Silk Road Economic Zone and the 21stcentury Maritime Silk Road, is a strategy of international regional economic integration initiated by China and actively pushed forward by senior Chinese officials. This strategy will set off the fourth wave of investment in China and provide new opportunities and motive powers for the sustainable economic development in China.

However, due to the inertia existing in the traditional systems and mechanisms as well as in the traditional development mode, the adjustment of China's economic structure is facing pains in the following four aspects: firstly, there is huge production capacity surplus in the manufacturing industries such as the steel industry, the cement industry, the shipbuilding industry and the electrolytic aluminium industry. Therefore, the production capacity of the manufacturing industries has to be reduced. Secondly, the debt ratio of local government is relatively high. Therefore, the leverage of the finance industry has to be taken out. The third is the pain from the adjustment of real estate industry and the fourth is the pressure on the resources and environment. All these pains indicate that China's economy is facing great downward pressure, so the growth rate may be furtherly slowed down. With regard to this, the institutional barriers hindering the optimization and upgrading of the economic structure have to be eliminated by deepening the reform.

\section{THE OPTIMIZATION AND UPGRADING OF THE} ECONOMIC ST RUCT URE ARE PROMOTEDBY DEEPENINGTHE REFORM

Currently, the demographic and resource dividends tend to be cashed and the economic growth rate has been slowed down. Under this background, the deepening of the reform has become the motive power to achieve the optimization and upgrading of the economic structure and the promotion of sustainable and rapid economic development. As early as 1995, Chinese government explicitly proposed to transform the mode of economic growth. However, after 20 years, the traditional mode of economic growth has not changed fundamentally. China's economic growth is still of low quality, which is rooted in its traditional systems and mechanisms.

In theory, only by setting up a whole set of efficient systems and forming effective motivation for the behaviors of the market entity and the government to make the market actively choose the production and business mode which is able to meet the needs of the sustainable development, can the mode of economic growth be transformed. In China, the rapid development for the past 30 years has given rise to the institutional barriers which fit the traditional mode of economic growth but are harmful to the transformation of development mode. For example, there are abundant disunity of market rules and department and regional protectionism, which lead to the severe similarization of industrial structure. The inadequacy of market competition and the massive existence of monopoly and discrimination against the systems, consciousness and policies of the private enterprises prevent the market from weeding out the bad from the good and adjusting the economic structure. Only by deepening the reform and eliminating the institutional barriers which impede the free flow of goods, labor and other production factors to ensure market's decisive role in resource allocation, can the optimization and upgrading of the economic structure be achieved and the quality and efficiency of economic development be improved.

In the first place, the new-type urbanization has to be promoted. The key is to deepen the reform of the household registration system: Aiming at the urban and rural integration, migration freedom and non-benefit, the benefits attached to the household registration are gradually to be removed. Besides, equal rights are to be granted to the transient population in terms of labor employment, salary, the education of children, social security and so on. In rural areas, the reform of the land system has to be deepened and the transferability and the market-oriented allocation of the land resources have to be achieved. In this way, the rural residents are given more added values from land to provide financial support for them to take part in urbanization. In addition, the reform of the housing system has to be deepened, incorporating the migrant workers into the urban housing security system.

In the second place, the modern industrial system has to be set up. The new system of modern industry, which is the mutual confusion and the organic integration of advanced manufacturing industry, modern agriculture and modern service industry, is the third complete promotion of the traditional industry. The fundamental motive power for the adjustment of the industrial structure comes from the market competition. Therefore, the equal usage of the production factors and the fair participation in competition by diverse-ownership economies are to be ensured by deepening the reform. A sound market is to be nurtured by the government and market economy cannot do without government. In view of this, the functions of the government have to be transformed and the law-oriented and service-oriented government is to be constructed in order to provide necessary public products and public services to the society in a better way. Besides, the government should also make good use of the negative list to manage the market so as to ensure the free flow of production factors and the promotion of the optimization and upgrading of the economic structure.

In the third place, the regional economic integration is to be promoted. In recent years, the gap of economic development between different regions in China has been slightly narrowed down. However, regional economic development is still facing the problems of the confusion of the relationship between cooperation and division, the frag mentation in the regional planning and policies and so on. Therefore, a sound system of regional planning and regional policies should be gradually set up and improved so as to make full use of the fiscal, tax and financial 
policies to guide the flow of resources and improve the efficiency of resource allocation. In the process of implementing the strategy of "One Belt and One Road", the market orientation has to be stuck to and the functions of the market, enterprises and government at all levels have to be reasonably defined and exerted in order to form the joint power. Besides, the dominant role played by enterprises in the trade and investment cooperation has to be determined and the participation of the private enterprises has to be encouraged.

In addition, the optimization and upgrading of the economic structure by deepening the reform also involve the reform of various fields such as the income distribution system, financial and banking system, state-owned enterprises, administration system and so forth. Under the background of the new normal, the key to success of the optimization and upgrading of the economic structure lies in whether the deepening of the reform can achieve substantial progress and whether the new motive power for economic development can be formed at a fast speed.

\section{REFERENCES}

[1] Wang Yueping. "The Pursuit of the Adjustment of Industrial Structure with High Quality and Efficiency". Macroeconomic Management 2014(10)

[2] Liang Feng. "On the Challenges Facing the Society and Economy in China". Economic Research Guide. 2014 (35)

[3] Li Jinhua. "The Promotion of the Adjustment of Industrial Structure Based on Reform". Economic Daily. March 25th 2014.

[4] Gu Shengzu. "The Six New Opportunities and Challenges Facing the New Normal". Economic Daily. Feburary 5th 2015.

[5] Lv Hongxing. "New Normal", both the challenge and opport unity". China Economic Times. September 4th 2014.

[6] Li Zuojun. "The Huge Productivity of Structural Optimization in China “. China Economic Times. March 27th 2015.

[7] The Teaching and Research Department of Economics in Chinese Academy of Governance. China's New Normal of Economy People's Press, 2015

[8] Li Yang, Zhang Xiaojing, On the New Normal of Economy, People's Press, 2015

[9] Ding Maozhan, Economic Growth and Transition are all the Historical Mission of China's New Normal, Reference News of Economy, Feb.27th, 2015

[10] Zhang Zhanbin, the New Normal is the Broad View of .Logic of Economic Development, Liaoning Daily, March. 11 $1^{\text {th }}, 2015$ 